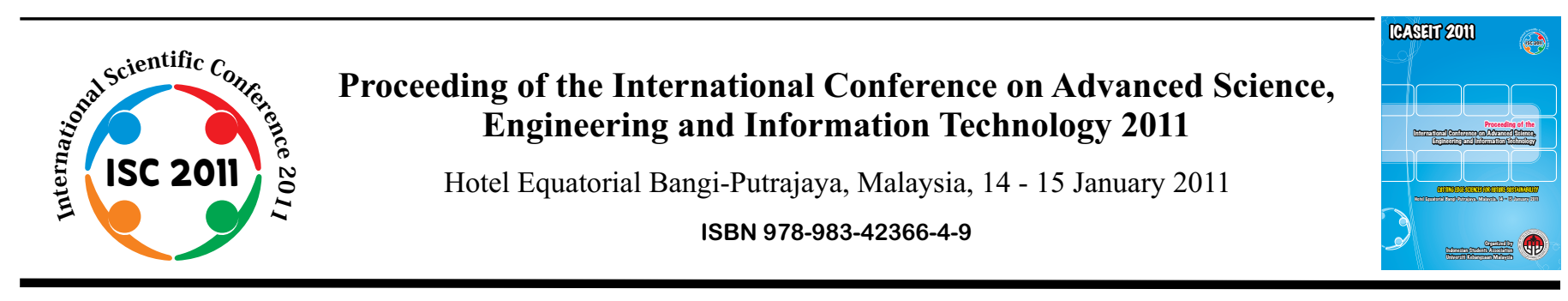

\title{
The ICT Revolution and Its Impacts on the Future Women Workforce in Malaysia
}

\author{
Oras F. Baker ${ }^{1}$, Kasthuri a/p Subaramaniam ${ }^{2}$ \\ ${ }^{1}$ Faculty of Management\& Information Technology, UCSI University \\ Kuala Lumpur, Malaysia \\ Iorasbaker@ucsi.edu.my \\ ${ }^{2}$ kasthurisuba@ucsi.edu.my
}

\begin{abstract}
ICT is a highly dynamic field as it keeps changing very rapidly over time. Due to its dynamic nature, the manpower involve in the ICT field need to be trained and retrained to be able to cope with the changes. Women represent $36 \%$ of the Malaysian workforce according to official statistics. The empirical findings in this study reveal that the majority of the women employees indicated that they need more training to handle ICT. This study will find out the impacts of the ICT revolution on the future of women workforce in Malaysia.
\end{abstract}

Keywords- Gender, ICT, Manpower, Workforce.

\section{INTRODUCTION}

Ever since the Industrial Revolution there has been an ongoing debate over the impact of technology on employment. This debate continues today in what is widely recognized as the second industrial revolution information technology. The objective of this research is to examine the impact of information technology on women's employment in Malaysia. Malaysia is a practical country to look at, given the present acceleration towards rapid industrialization and the government's intention to make information technology (IT) one of the key technologies in the nation's bid to become a developed country by the year 2020. It is agreed that the emergence of Internet and its electronic devices has changed many aspects of lives such as the way people communicate, work, learn, play, do business and so on. Clearly the applications of Information Technology have been implemented with the aim to improve productivity or services in the workplace. Women represent $36 \%$ of the Malaysian workforce according to official statistics [1]. However, half of this comprises women working as unpaid, family workers. Although the number of economically active women has increased, the largest growth in women's participation has been in middle- and low-level jobs, such as clerical and production worker. And while more women are entering professional sectors, this is largely restricted to nursing and the teaching professions. However, without the adequate and skilled human resources the implementation of Information Technology in all sectors will lead to failure. Recognizing this fact, for developing countries like Malaysia, the development of human resources is as critical as acquiring the hardware, software and other systems components in order to utilize the full potential of Information Technology for the nation to progress. In particular the human resource development of women should support their ability to participate in national development and contribute to economic growth. As mentioned earlier, the IT revolution has changed many aspects of lives and the human resources development is no exception. This paper will draw attention to the common issues in the Information, Communication and Technology (ICT) Revolution and its impacts on the future of women workforce in Malaysia and some of the changes in the requirements in job seeking in the market.

\section{THE ICT REVOLUTION AND ITS IMPACTS ON WOMEN WORKFORCE}

Undeniably ICT has great impacts on manpower requirements. The Malaysian worker women must have 
knowledge on the ICT applications, specifically using the Internet for marketing, advertising, customer service and support, ordering, delivery and payment. The advent of ICT requires that the current and future women workforce of Malaysia be computer literate, have strong business application skills, and therefore a flexible and multi skilled women workforce is necessary. The changing requirements in human resource means the government along with the private sectors have to invest more in education, especially to produce more computer literate workforce [1], [2], [3], [4]. These skill requirements place new demands on schools and vocational training facilities to be improved. A system of education that familiarizes young students with the technology of the Internet can greatly reduce skills acquisition costs and decrease the participation rates of ICT in the various segments of society. ICT is a highly dynamic field as it keeps changing very rapidly over time. The present women employees can easily be trained on-the job so that they do not have to spend too much money and thus many workers can be trained at the same time.

In general, it is agreed that the infrastructures for ICT applications are adequate but the human resource to handle them are still insufficient. Electronic commerce is a manifestation of the digital economy, which is considered the main part of the ICT revolution. In this research we will consider women's participation and knowledge of ecommerce as a case study.

The government also can accelerate the E-commerce applications in the business industry by implementing stricter policies regarding security using Internet by enforcing stricter rules to protect consumers doing transactions on-line.

A survey was conducted with full cooperation from the three companies, Ericsson, Intel and Motorola respectively and other small and medium scale Information, Communication and Technology related companies located around Klang Valley.

Based on the response of the survey, it was found that lack of knowledge, skill and difficulties in keeping up with the technology is the main problem to implement Ecommerce. Furthermore not all organizations provide training to their employees. Therefore, it is recommended that every organization have a structured training program that follows a planned training guideline, as the acquisition of specific skills in E-commerce is essential. Thus, it is hoped that training guidelines will be formulated by the organizations involved and the related agencies.

The government also is recommended to provide more computer facilities to the students in urban as well as in rural areas. This is to provide equal opportunity to all students so that they are computer literate at an early age, creating and strengthening alternative networks and channels for women's advocacy.

With the convergence of ICT and the emergence of what is being called the 'information' or 'knowledge' society, development strategists also see the need for developing countries should adapt ICT as a potential force not only for creating new economic growth opportunities but also for enhancing political participation of citizens.

\section{STATISTIC WOMEN WORKFORCE IN MALAYSIA}

From 1997 to 2008 the statistics shown that male labour remain high in percentage as compared to female labor, from 84.4 to 79.0 in 1997 to 2008 for male and from 46.0 to 45.7 for women as shown in figure 3.1 .

Only between the years 2000 to 2004 did female labor increase to quite huge numbers but still far behind compared to male labor, from 83.0 to 80.0 as shown in figure 3.1. [1], [2].

In reviewing and developing policies and corresponding strategies and programs, it is critical to ensure that the gender dimensions are equally addressed in order to increase the women's participation in the ICT field and ultimately the economy as well.

In Malaysia the numbers of women workers are still far behind compared to another advance country such as Great Britain and United State of America.

The statistics of the Labour force participation rate by Gender, 1997-2008 show that the number of females employed not more than half of the Malaysian population.

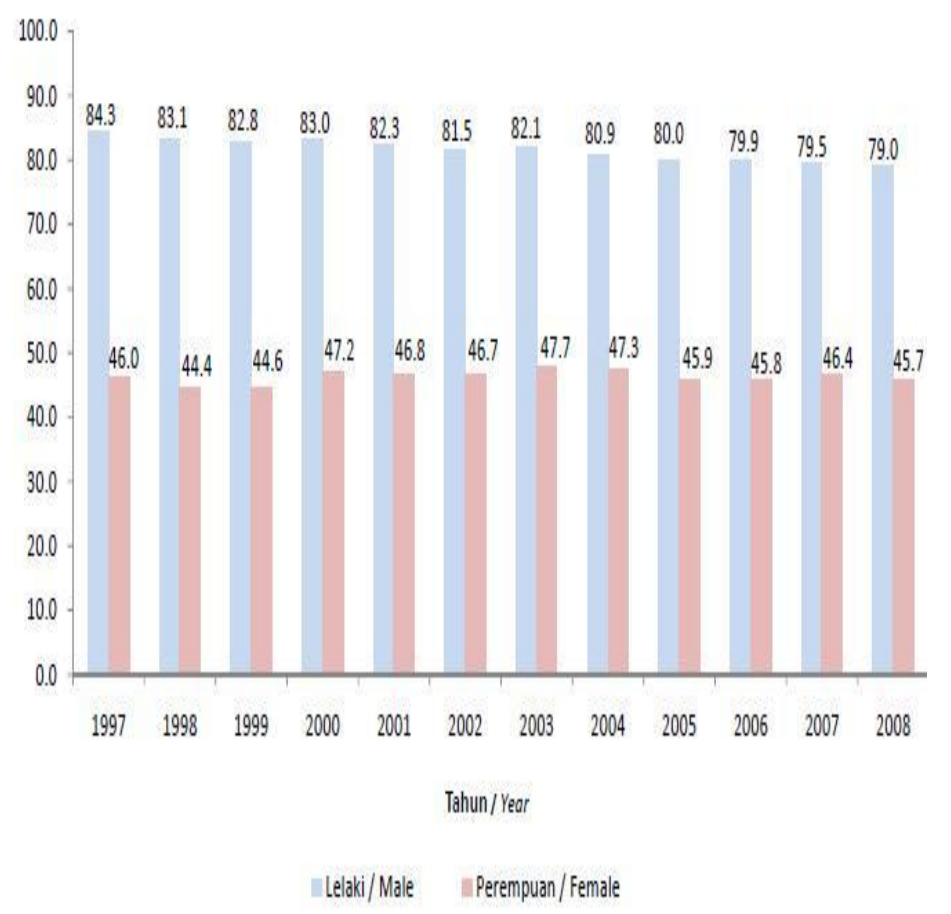

Fig 3.1 Labour force participation rate by Gender, 1997-2008

From 1997 to 2008 the statistics of employment show that female unemployment rate increased from $2.8 \%$ to $3.7 \%$ for the same period of time as shown in figure 3.2. 


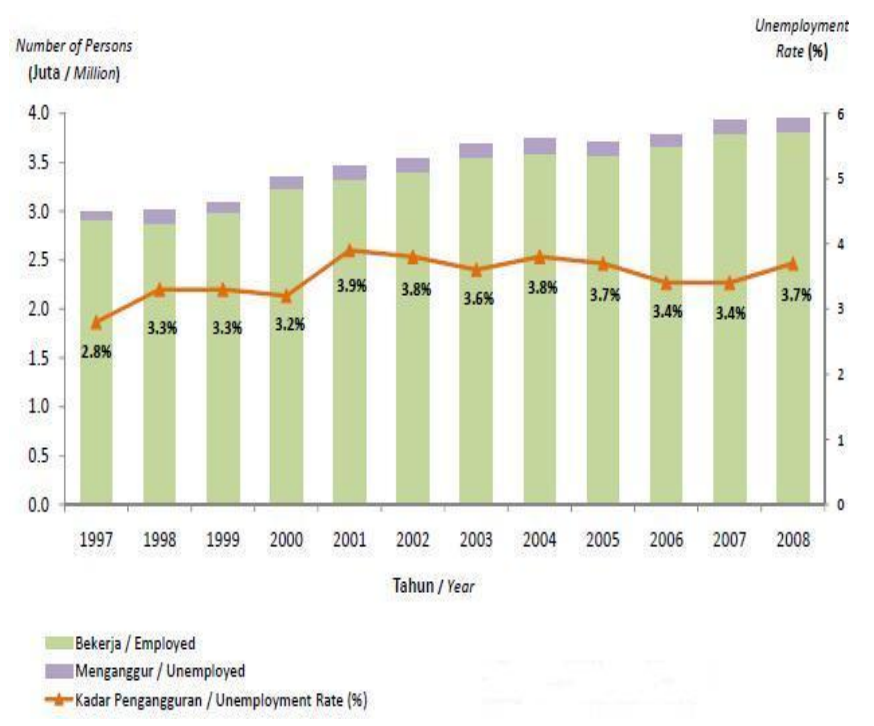

Fig.3.2, Total labour force, number employed and unemployment rate (Female), 1997-2008.

\section{E-COMMERCE TRAINING CROSS TABULATION OF THE MANPOWER}

There are two kinds of data in this study, primary and secondary data. The primary data was collected from the surveys which were conducted by the researcher meanwhile the secondary data was obtained from various books, journals, articles, news paper and internet search. Only 55\% out of 100 questionnaires were responding. To overcome this problem the researcher posted questionnaire via group email, but unfortunately only 4 respondents were received.

Due to the dynamic nature, the manpower of the ICT field need to be trained and retrained to be able to cope with the changes. The empirical findings in this study reveal that the majority of the women employees indicated that they need more training to handle E-commerce and ICT [1]. The sampling frame was obtained with full cooperation from the three companies, Ericsson, Intel and Motorola respectively and other small and medium scale Information, Communication and Technology related companies located around Klang Valley. The tabulation of ICT training group by sex shown in Figure 4.1 and Figure 4.2.

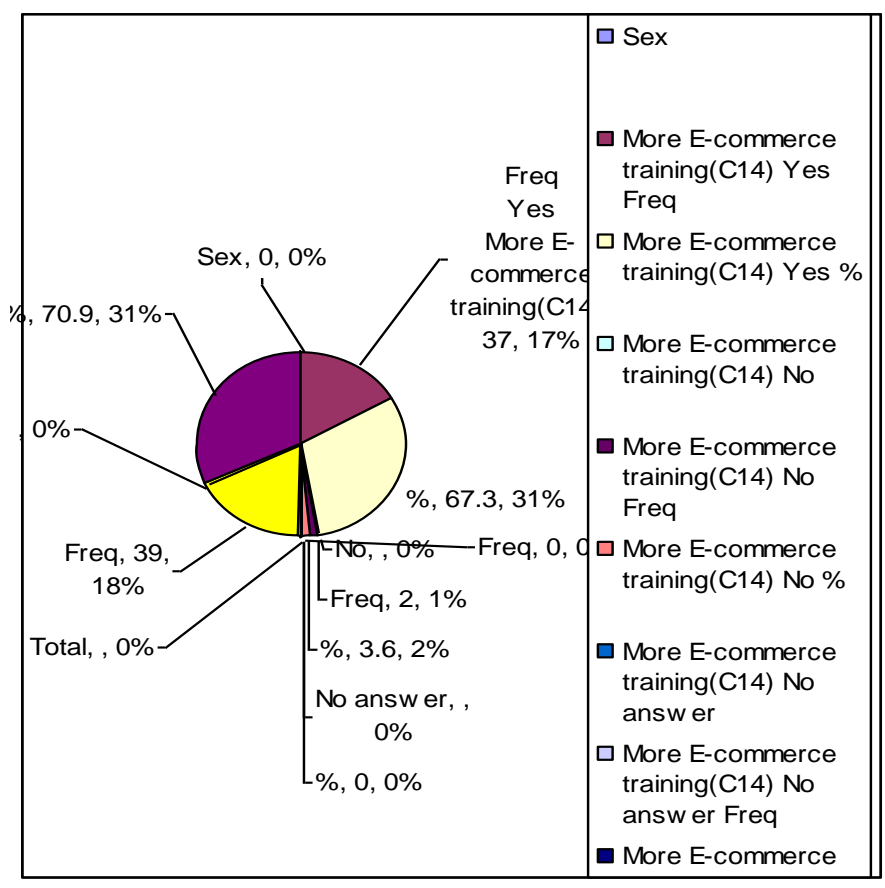

Fig 4.1, Training respondents based on gender.

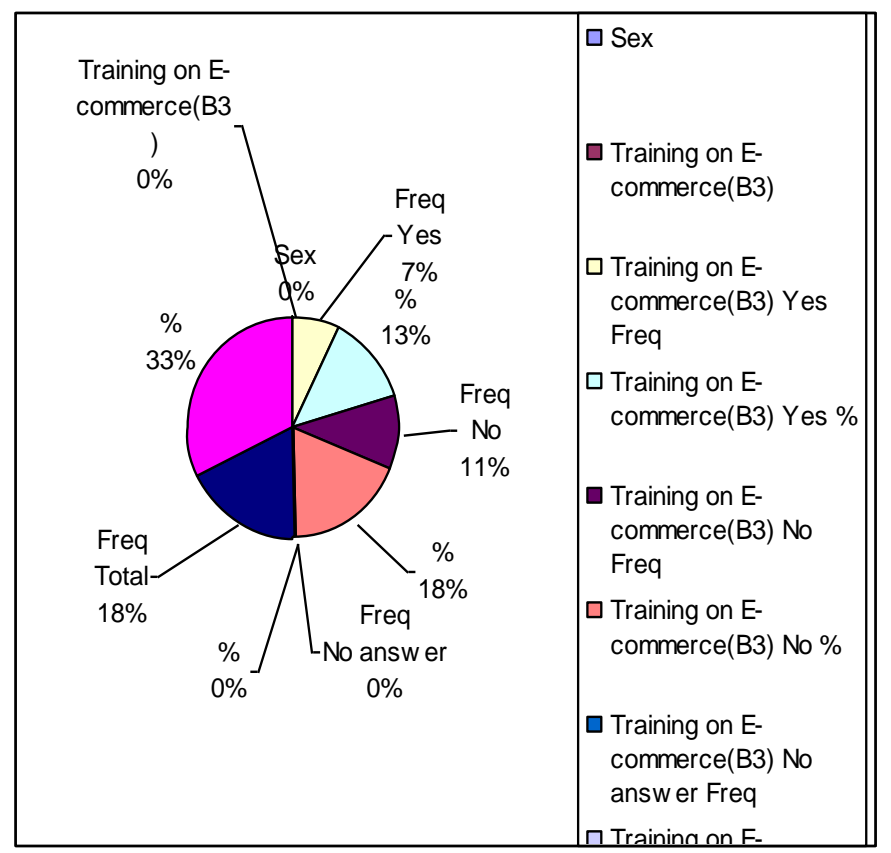

Fig 4.2, Respondent who already went for trainings.

From the Figure 4.1 above, 37 male respondents indicated that they needed more training on E-commerce and only 2 respondents indicated that they did not need more training. On other hand, out of 16 female respondents, 10 indicated more training, 2 indicated did not need more training and the rest did not respond. From the Figure 4.2 only $3.6 \%$ female took training out of 29.1 respondent compared to $29.1 \%$ male took training out of 70.9 male respondents. 


\section{WOMAN IN ICT}

The growth of the e-economy, potentially offers possibilities for business and self-employment even to women who are not privileged, and are employed in the informal sector of the economy. Women in the informal sector need to be innovative in finding niche markets, in the same way as the corporate sector, in order to participate in ICT. The changing scenario from a woman's perspective, women particularly the non-privileged ones in the informal sector, need market information and business skills as much as hardware, software and connectivity to be able to participate in ICT [8], [9]. Representatives of women's NGOs conference may benefit from a dialogue with the donor bodies and the policymakers to identify experts who could make market information available to miniscule women entrepreneurs and help women to get connected to websites.

In an ever-expanding digital economy and ICT that is facing acute shortages of requisite business and technical skills, women could redress the skills shortages faced by the private sector - so long as they have initial access to technical and business training, infrastructure and/or credit[8],[9]. It would be rather un-strategic to assume that the needs and visions of all women are the same, and that all women in the developing world view ICT with uncritical enthusiasm.

\section{OBSTACLES IN UTILISING ICT TO INCREASE THE WOMEN WORKFORCE IN MALAYSIA}

Like elsewhere in the world today, Malaysians are opening up to the idea of ICT technology. Malaysian citizens have begun to experience the reality of the Information age, whether they realize it or not. However, the main problem Asian companies in general and Malaysian companies in particular will face is the shortage of manpower in deploying electronic commerce. This is because internetworking and electronic commerce technology keeps changing; companies in Asia will have to find skilled ICT staffs that can asses to meet the challenge of this fast emerging filed. However, Malaysia is fortunate because of the strong support and commitment of the government towards electronic commerce. Furthermore, the government through MSC provides the infrastructure to facilitate the growth of electronic commerce and it is up to the people to do the rest to live up to the expectation.

There are multiple challenges to ICT becoming a positive force for women's economic empowerment. Few participants directly referred to expense as a barrier. Financial resources are only one of the many resources needed to make ICT available and effective. Challenges include:

- The large percentage of women who work in the informal sector

- The lack of support for women working in the formal sector

- The lack of access to ICT and ICT training - especially for rural women;

- A lack of awareness of women to the benefits of ICT

- Language barriers to the use of ICT for non-native speakers of English

\section{CONCLUSION}

The impact of ICT to social, political and economic changes has arguably become the major development concern for many governments. In the last few years, 'Women' and 'ICT' in the same analysis presents further challenges on how to simultaneously reduce gender disparities and ICT barriers for equitable development. A large amount of progress has been achieved in the past few decades in narrowing the gender gap in Malaysia through enhancing the national mechanism for women's development, increase women's participation in decision-making, and safeguards women's rights to health, education and social well being, and removes legal obstacles and gender discriminatory practices. However more steps should be taken to increase the women participation in the ICT economy sector such us;

- Promote the consideration and incorporation of gender in ICT policy-making bodies and forums.

- Initiate and implement research activities in the field of gender and ICT.

- Advance the body of knowledge, understanding, and skills in the field of gender and ICT by implementing training activities.

- Facilitate access to information resources in the field of gender and ICT.

\section{REFERENCE}

[1] Hassani, Oras Fadel Baker Al. A study on the impacts and implications of electronic commerce (E-commerce) on manpower requirements in Cyberjaya, Malaysia /. 2001. Dissertation (M.Comp.Sc.) - faculty scince computer and information technology, University Malaya, 2002. QA76 UM 2002 Has

[2] Zwass, V. (1996). "Electronic Commerce: Structures and Issues", International Journal of E-Commerce, Vol. 1, No. 1, Fall 1996, pp. 3-23.

[3] Coulston-Thomas, Collin J. (1997). "Using Electronic Commerce to Reengineer Supply Chains", Focus on Change Management, December 1996 / January 1997, Issue 30, pp. 9- 13 .

[4] Rahmah Ismail and Idris Jajri. (1998). Human Capita and Economic Growth in Malaysia: A Simulation Model, Kajian Malaysia, Vol. XVI, No. 1 \& 2, pp. 78-88.

[5] National Productivity Corporation (NPC) \& University of Malaya. (2000). Electronic Commerce (E-Commerce) Applications in Malaysia 1999. Petaling Jaya.

[6] Ministry of women,

[7] http://www.kpwkm.gov.my/new_index.php?page=statisti c_content\&year $=2009 \&$ lang $=$ eng

[8] .http://www.wao.org.my/news/20010301statusreport.htm \#Work

[9] http://www.apcwomen.org/summit/policy/asia/EGM\%20 UNDAW\%20\%20Regional\%20Perspective\%20Asia\%20 -\%20CG\%20Ramilo.doc

[10] .http://www.nitc.org.my/spress/speeches 